\title{
Hidroxicloroquina: Uso Potencial em Coronaviroses?
}

\author{
Dany Geraldo Kramer ${ }^{1}$, Geraldo Barroso Cavalcanti Junior ${ }^{2}$, Nathalie de Sena Pereira ${ }^{3}$
}

\begin{abstract}
RESUMO
A hidroxicloroquina ( $\mathrm{HCQ}$ ) é um análogo da cloroquina, que foi sintetizada para a terapêutica da malária. Ao longo das últimas décadas têm se observado o potencial de aplicação em outras patologias, como doenças autoimunes, oncologia e infecções virais. Neste último grupo, enquadra-se a discussão sobre o uso de HCQ diante do desafio imposto pela pandemia causada pelo novo coronavírus com início em 2019, causador da doença conhecida como Covid-19, que têm infectado centenas de milhares de pessoas e acarretado em milhares de mortes em todo mundo. Nesta conjuntura, objetivou-se discorrer acerca do uso potencial da HCQ em infecções causadas por coronavírus. Mediante estudos revisados, observou-se que a HCQ pode inibir a replicação viral em sistemas in vitro pelo seu acúmulo no lisossomo e complexo de Golgi celular, apresentando baixo custo. Não há, entretanto, evidência quanto à sua eficácia e existem diversas reações adversas e contraindicações clínicas. Além disso, ensaios clínicos randomizados, cegos, de tratamentos de coronavisores, devem ser estabelecidos, de forma que protocolos clínicos possam ser adequadamente utilizados para o tratamento da Covid-19.

Palavras-chave: Hidroxicloroquina. Coronavírus. Terapêutica.
\end{abstract}

HYDROXICLOROQUINE: IS THERE A POTENTIAL USE AGAINST CORONAVIRUS?

\section{ABSTRACT}

Hydrochloroquine (HCQ) is an analogue of chloroquine, which was designed for malaria therapy. Over the past few decades has been observed. the potential for application in other pathologies, such as autoimmune diseases, oncology and viral infections. In this sense, HCQ has been investigated for use against coronavirus disease 2019 (Covid-19), which has infected hundreds of thousands of people and resulted in thousands of deaths worldwide. The objective was to discuss the potential use of HCQ in coronovirus infections. Based on this revision, it was observed that HCQ could inhibit viral replication in vitro due to its accumulation in the lysosome and cell Golgi complex and presenting low cost. However, there is no evidence regarding its effectiveness and there are several adverse reactions and clinical contraindications. In conclusion, randomized, blinded, clinical trials about coronavirus treatments needs to be concluded to provide clinical protocols for Covid-19.

Keywords: Hydroxychloroquine. Coronavirus. Therapy.

RECEBIDO EM: 22/3/2020

MODIFICAÇÕES SOLICITADAS EM: 30/3/2020

ACEITO EM: 19/4/2020

\footnotetext{
${ }^{1}$ Professor doutor do Programa de Pós-Graduação em Saúde da Família - Renasf. UFRN. http://lattes.cnpq.br/8363044275404035. http://orcid.org/00000001-7655-7444.dgkcs@yahoo.com.br.

2 Professor doutor da UFRN. Farmacêutico Bioquímico. http://lattes.cnpq.br/0091662650633339. https://orcid.org/0000-0001-9227-4145. gbcjunior2@ hotmail.com.

${ }^{3}$ Professora doutora da Universidade Potiguar. Biomédica. http://lattes.cnpq.br/6882923707364191. https://orcid.org/0000-0002-0148-177X. nathalie. sena@hotmail.com.
} 


\section{INTRODUÇÃO}

A cloroquina (CQ) é uma 9-aminoquinolina que foi sintetizada, em 1934, como alternativa ao quinino para o tratamento da malária. Na sequência, foi sintetizado seu hidroxi-análogo hidroxicloroquina (HCQ) como alternativa complementar ao tratamento da malária (PLANTONE; KOUDRIAVTSEVA, 2018; BALEVIC et al., 2019; CHANG; SUN, 2020).

Em decorrência de mecanismos de ação variada, a HCQ tem apresentado variada aplicação clínica, dentre as quais doenças reumáticas, oncológicas e infecções virais (KUMAR et al., 2018; CHEW et al., 2019). Isto decorre dos mecanismos propostos que incluem: Interferência na atividade lisossomal e Complexo de Golgi, Inibição da atividade de macrófagos e Inibição da ativação de mastócitos e linfócitos, resultando na interferência na produção de mediadores inflamatórios e replicação do microrganismo (PONTICELLI; MORONI, 2016; SHI et al., 2019; SCHREZENMEIER; DÖRNER, 2020).

Quanto às posologias de aplicação da $\mathrm{HCQ}$, recomenda-se não ultrapassar $6,5 \mathrm{mg} / \mathrm{kg}$ de peso corporal real ou $400 \mathrm{mg} / \mathrm{dia}$, o que for menor, para reduzir o risco de retinopatia. Deve-se atentar para as contraindicações de uso, dentre as quais pacientes com maculopatia pré-existente e aqueles que tenham hipersensibilidade aos derivados da 4-aminoquinolina (SHI et al., 2017; BALEVIC et al., 2019; CHEW et al., 2019; SCHREZENMEIER; DÖRNER, 2020). Em decorrência da severidade clínica e ausência de opção terapêutica, entretanto, estudos investigam o uso da $\mathrm{HCQ}$ no tratamento da Covid-19 com doses entre 500 a 600 mg, 2 vezes ao dia, por 5 dias (YAO et al., 2020; GAUTRET et al., 2020).

A HCQ apresenta, entre as reações adversas mais comuns, a Retinopatia, sendo estimada ocorrência em $7,5 \%$ dos pacientes por 5 anos ou mais, podendo causar perda permanente da visão, que pode continuar a progredir após a interrupção do medicamento, e Reações cutâneas, podendo ocorrer em 5\% dos pacientes. Dentre os achados mais comuns têm-se erupções morbiformes e psoriasiformes (CHEW et al., 2019). Efeitos adversos hematológicos ocorrem raramente, embora possam ser observados agranulocitose, anemia aplástica e leucopenia. Reações gastrointestinais podem ser observadas em torno de $2 \%$ dos pacientes, sendo mais comuns os sintomas de náusea, vômito e diarreia (SCHREZENMEIR; DÖRNER, 2020; ROWANE et al., 2020).
Esta substância, $H C Q$, vem sendo objeto de estudo para aplicação em infecções virais, dentre as quais Zika vírus, Hepatite A, HIV e, mais recentemente, atuação sobre fases de replicação do coronavírus (KUMAR et al., 2018; PLANTONE; KOUDRIAVTSEVA, 2018; DEVAUX et al., 2020). Relativo às coronaviroses, a HCQ pode representar uma contribuição potencial como ferramenta farmacológica disponível, uma vez que não existem tratamentos antivirais específicos até o momento (YAO et al., 2020). Os vírus da família de coronavírus vem causando pandemias e surtos ao redor do mundo com centenas de milhares de infectados e dezenas de milhares de mortos, sendo, mais recentemente, observados os surtos: Sars-CoV-1, que surgiu em março de 2003 na China, o Mers-CoV, que surgiu em 2012 no Oriente Médio e o Sars-CoV-2, causador da Covid-19 na China, que se tornou uma pandemia (HUANG et al., 2020; DEVAUX et al., 2020; ZHANG et al., 2020). Neste sentido, o presente estudo objetivou discorrer acerca do uso potencial da HCQ em infecções causadas pelo coronavírus.

\section{CORONAVÍRUS E A COVID-19}

Os coronavírus são um conjunto de vírus que ocorrem em aves e mamíferos, sendo pertencentes à família coronaviridae. Estes recebem esta denominação por suas partículas virais se assemelharem à coroa solar (grego korốnē) sobre a microscopia eletrônica. Esses vírus têm sido associados a surtos e pandemias, dentre as quais: Sars-CoV in 2003, Mers-CoV in 2012 e Covid-19 (GIWA; DESAl, 2020; HUANG et al., 2020; MUNSTER et al., 2020).

Apresentam-se como vírus envelopados e um genoma de RNA de fita simples, como formas esféricas ou pleomórfica (CHEN; LIU; GUO, 2020). O envelope do viral é constituído por uma bicamada lipídica na qual as proteínas estruturais da membrana e as glicoproteínas estão ancoradas, sendo estas responsáveis pela ligação inicial do vírus ao receptor de célula hospedeira complementar (GIWA; DESAI, 2020; MALIK et al., 2020).

Assim, a replicação do Sars-CoV-2, causador da Covid-19 (Figura 1), inicia-se pela ligação à glicoproteína viral ao receptor da célula-alvo, esta induz à adsorção, que leva à formação do fagossoma celular, com consequente internalização (endocitose) do vírus. Esse processo direciona o vírus para o compartimento lisossômico, em que o baixo $\mathrm{pH}$, juntamente com a ação das enzimas, promove o desnudamento da partícula viral, liberando o ácido nucleico infeccioso e, em vários casos, as enzimas necessárias para a replicação viral. O material genético (RNA) é, então, 
Figura 1 - Ciclo do Coronavírus Sars-CoV-2 (Covid-19)

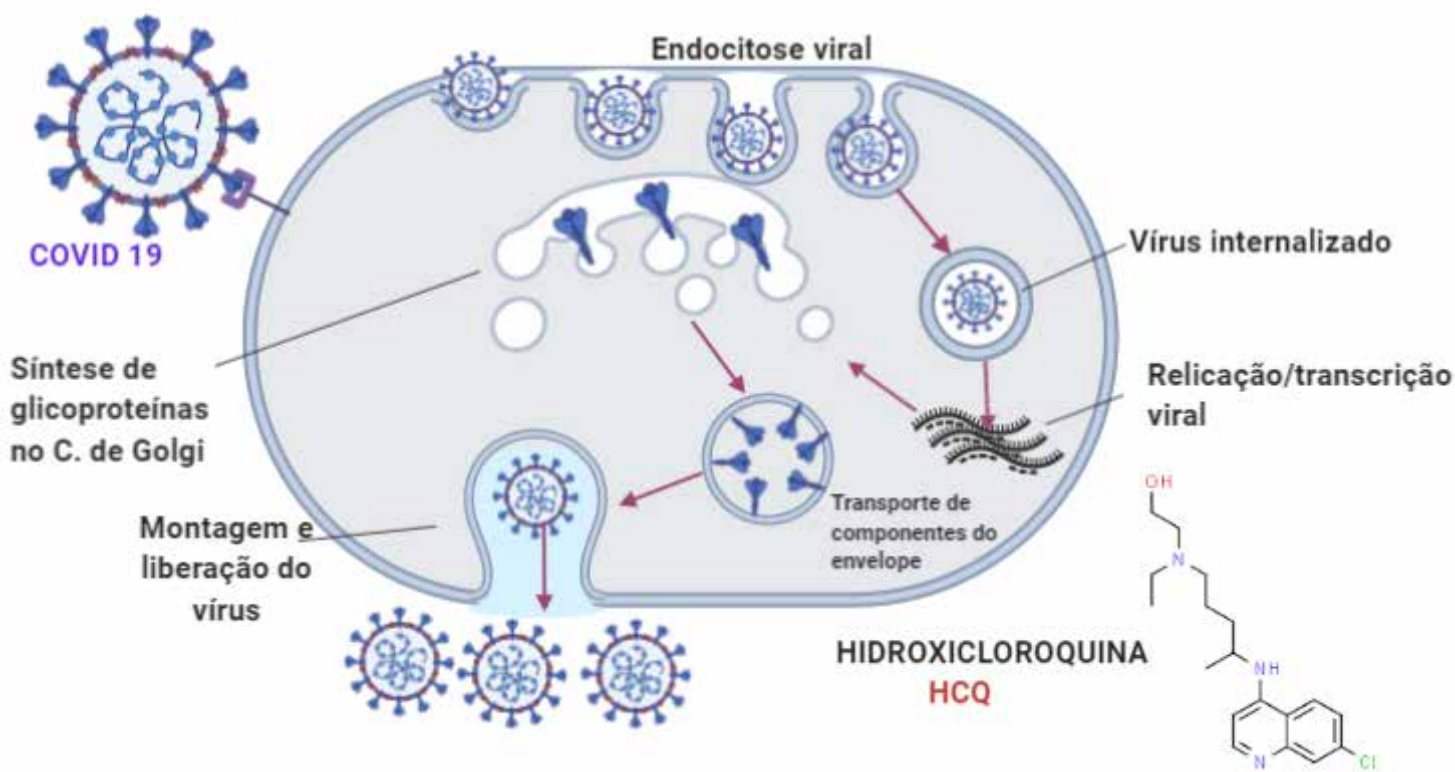

Inicia-se pela ligação à glicoproteína viral ao receptor da célula-alvo, com posterior endocitose viral e a formação do fagossoma celular, com consequente internalização do vírus. Esse processo direciona o vírus para o compartimento lisossômico, em que o baixo pH, juntamente com a ação das enzimas, promove o desnudamento da partícula viral, liberando o ácido nucleico infeccioso e, em vários casos, as enzimas necessárias para a replicação viral. O material genético (RNA) é, então, replicado, levando à síntese de estruturas virais, tais como capsídeo, envelope e demais proteínas, principalmente glicoproteínas no complexo de Golgi celular. O vírus, nesse momento, é montado e é liberado da célula hospedeira por exocitose.

Fonte: Autoria própria. "Created with BioRender.com".

replicado, levando à síntese de estruturas virais, tais como capsídeo, envelope e demais proteínas, principalmente glicoproteínas no complexo de Golgi celular. $\mathrm{O}$ vírus, nesse momento, é montado e é liberado da célula hospedeira por exocitose (CHEN; LIU; GUO, 2020; DHAMA et al., 2020).

O coronavírus é transmitido, principalmente, por meio de gotículas respiratórias geradas por espirros e tosse, sendo relatada, ainda, a transmissão por alimentos e objetos contaminados por partículas virais. Supõe-se que a maior parte dos infectados apresentem sintomatologia semelhante ao resfriado comum - febre, dor de garganta, tosse, espirro e dor muscular (DHAMA et al., 2020; HUANG et al., 2020). O coronavírus pode causar pneumonia (pneumonia viral direta ou pneumonia bacteriana secundária) e bronquite (bronquite viral direta ou bronquite bacteriana secundária) (CHEN; LIU; GUO, 2020; GIWA; DESAI, 2020; HUANG et al., 2020).

\section{MECANISMO DE AÇÃO E USO TERAPÊTUICO DA HCQ}

Até o momento não há um antiviral específico para o tratamento das infecções da Covid-19, sendo, basicamente, suporte, incluindo-se o uso de antitérmicos, analgésicos e suporte ventilatório e renal para os casos mais graves. Algumas drogas, entretanto, têm sido observadas como potencial, dentre as quais a HCQ, sendo considerada uma contribuição válida como ferramenta farmacológica disponível para os casos mais graves (VERBAANDER et al., 2017; SHI et al., 2017; MARMOR, 2019; CHEW et al., 2019; ZHANG et al., 2020).

Um dos mecanismos de ação da HCQ está ilustrado na Figura 2, na qual esta droga entra e se acumula nos lisossomos dos macrófagos, alterando o pH destes, gerando uma estabilização de lisossomo e inibição de enzimas desta organela (ERKAN et al., 2018; SCHREZENMEIER; DÖRNER, 2020). A inibição da atividade lisossômica pode impedir a apresentação de autoantígeno mediada por MHC classe II, realizada pelos macrófagos. Em cadeia, observa-se a inibição da ativação de mastócitos e neutrófilos, e interrompe a sinalização de cálcio dependente do receptor em células T. Desta forma, a produção de mediadores inflamatórios é inibida, dentre as quais o fator de necrose tumoral alfa (TNF $\alpha$ ), Interleucinas (1 e 6) e interferons, reduzindo, assim, o processo inflamatório (PONTICELLI; MORONI, 2016; BALEVIC et al., 2019).

No que se refere à utilização em infecções virais, como a Covid-19, tem sido proposto que a HCQ se acumula nos lisossomas e complexo de Golgi da célula infectada, alterando o pH destas estruturas (Fi- 
Figura 2 - Mecanismo de ação da HCQ sobre a resposta imune

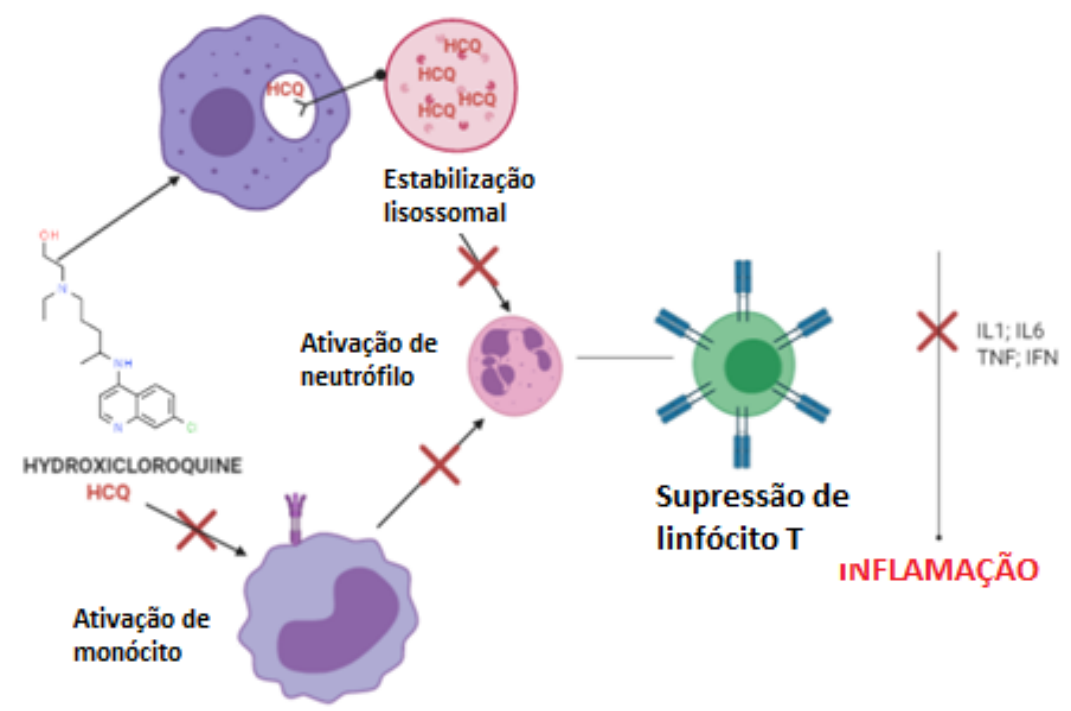

A HCQ acumula-se nos lisossomos dos macrófagos, alterando o pH destes, gerando uma estabilização de lisossomo e inibição de enzimas desta organela. A inibição da atividade lisossômica pode impedir a apresentação de autoantígeno mediada por MHC classe II, realizada pelo macrófago. Em cadeia observa-se a inibição da ativação do mastócito e neutrófilos.

Fonte: Autoria própria. "Created with BioRender.com".

gura 3). A nível de lisossoma, observa-se a estabilização da membrana lisossômica e inibição de enzimas, impedindo, assim, o desnudamento da partícula viral e bloqueando a liberação do genoma viral, que seria utilizado na replicação/transcrição. Já no complexo de Golgi, a alteração de pH leva à inativação de várias enzimas, incluindo hidrolases ácidas, e inibindo a modificação pós-transducional de proteínas virais recém- -sintetizadas. Assim, a produção de elementos estruturais, como glicoproteínas, é bloqueada, impedindo a montagem da partícula viral que seria liberada (DYALL et al., 2017; ZHANG et al., 2020).

Na literatura são relatados o uso da HCQ para testes contra o Coronavírus, alguns in vitro e vivo. Yao et al. (2020) utilizaram células "vero" infectadas por Sars-CoV-2, sendo testados pelos autores diversas

Figura 3 - Possível mecanismo da HCQ sobre a replicação viral do Covid-19

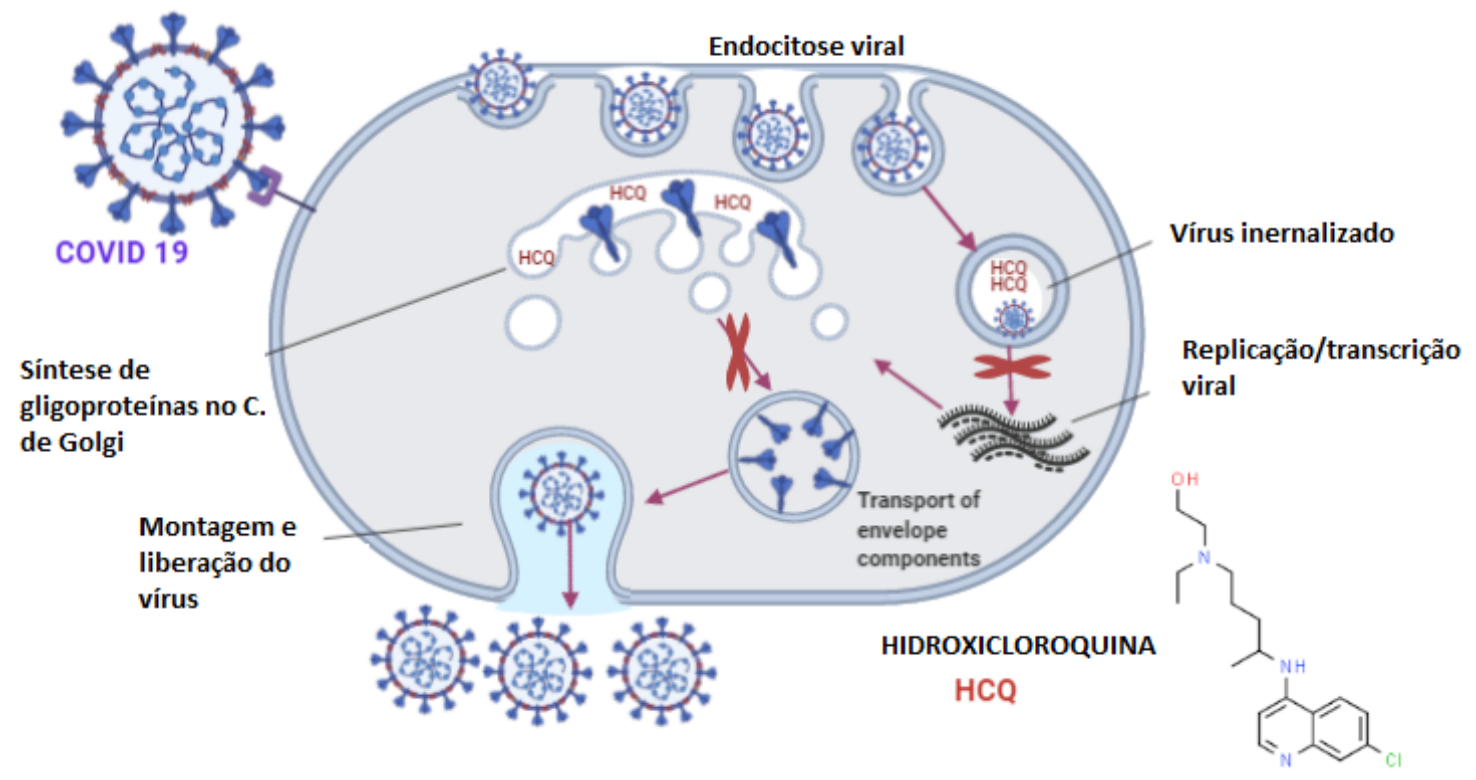

O vírus liga-se ao receptor celular e gera a endocitose viral, sendo internalizado. Na sequência, o Fagossomo gerado (lisossomo + vacúolo viral) tem a alteração do $\mathrm{pH}$ pela $\mathrm{HCQ}$, não ocorrendo o desnudamento viral. Assim, a transcrição viral não acontece. Ainda, observa-se o acúmulo da $\mathrm{HCQ}$ no complexo de Golgi, inibindo a síntese de partículas virais. Desta forma, a replicação do Covid-19 é inibida.

Fonte: Autoria própria. "Created with BioRender.com". 
dosagens, e sugerem, baseados nesses estudos, que a dosagem ideal seria de $500 \mathrm{mg}$ de HCQ/dia por 5 dias. Devaux et al. (2020) descrevem, em seu estudo, a aplicação de cloroquina e/ou HCQ associado com o antiviral remdesivir, sendo testados de formas preliminares em cem pacientes com Covid-19 na China, e observada, então, maior celeridade na reversão do quadro febril e pneumonia destes.

Borba et al. (2020) realizaram um estudo randomizado com 81 pacientes em Manaus, Brasil, com utilização de Cloroquina (CQ), sendo divididos em um grupo de alta dosagem (600mg CQ 2 vezes/dia por 10 dias) e um grupo de baixa dosagem (450mg 2 vezes/ dia no 1 o dia e 1 vez/dia por 4 dias). Os autores indicam que o tamanho limitado da amostra não permitiu demonstrar benefícios gerais em relação ao uso da CQ para pacientes graves com Covid-19, principalmente no grupo em alta dosagem, associada a efeitos mais tóxicos e letalidade, afetando, particularmente, o prolongamento do intervalo QT.

Mercuro et al. (2020) buscaram avaliar, por meio de um estudo de coorte realizado em um centro acadêmico de atendimento terciário em Boston (90 pacientes), a ocorrência de prolongamento do intervalo QT em pacientes com Covid-19 tratados com hidroxicloroquina, com ou sem azitromicina concomitante. Os autores constataram, semelhante ao obsevado por Borba et al. (2020), que alterações no intervalo QT podem ser potencializadas com o uso concomitante a outras drogas, tais como diuréticos de alça e azitromicina. Indicam, ainda, que é importante analisar outros fatores, como a cardiomiopatia estar associada ao Covid-19. São recomendados, portanto, estudos mais amplos e rigorosos para melhor avaliação dos beneficíos do uso da hidroxicloroquina.

Tang et al. (2020) realizaram um estudo multicêntrico na China com 150 pacientes, no qual alguns tiveram HCQ associada a agentes antivirais, antibióticos e terapia glicocorticoide sistêmica. Os resultados apresentados indicam não haver benefícios adicionais para o tratamento da Covid-19 em pacientes leves a moderados com HCQ, em relação aos tratamentos padrões vigentes, sendo apontados como reações adversas mais comuns distúrbios gastrointestinais.

Já Gautret et al. (2020) realizaram estudos clínicos com pacientes franceses diagnosticados com Covid-19 (6 assintomáticos e 30 com sintomas respitatórios). Os autores observaram que a utilização da HCQ havia acelerado a recuperação clínica dos pacientes em relação aos que não receberam a droga, vendo recuperação média em torno de 6 dias após o início do tratamento.
Picot et al. (2020) esclarecem que a urgência de testes clínicos é importante, devendo-se os pesquisadores não serem subjugados pela pressão social pelo uso descomedido da HCQ. Os autores destacam, no entanto, que o uso da $\mathrm{HCQ}$ em doses padrões àquelas aplicadas ao lúpus eritematoso sistêmico ( $6 \mathrm{mg} / \mathrm{kg} / \mathrm{dia})$, vêm apresentando-se com segurança e eficácia para o tratamento da Covid-19, corroborado o estudo clínico prospectivo desenvolvido por Perinel et al. (2020), que avaliaram a biodisponibilidade da $\mathrm{HCQ}$ em 13 pacientes com Covid-19, sendo sugerida uma dose inical de ataque e posologias ao menos de $200 \mathrm{mg} 2$ vez ao dia por 7 dias.

Conforme suprailustrado, os estudos apresentam dados conflitantes sobre o uso da HCQ para a terapêutica do Covid-19, entretanto são requeridos ensaios clínicos randomizados e cegos para melhor interpretação dos dados disponíveis. Neste contexto, em março de 2020 iniciou-se o estudo Recovery (do inglês, Randomised Evaluation of Covid-19 thERapY) que, em resposta a uma solicitação da Agência Reguladora de Medicamentos e Produtos de Saúde do Reino Unido, por meio de um comitê independente de monitoramento de dados, realizou uma nova análise dos dados. Este comitê concluiu que não há efeito benéfico da hidroxicloroquina em pacientes hospitalizados com Covid-19, e decidiram, portanto, interromper a inscrição dos participantes no braço da hidroxicloroquina do estudo Recovery. Um total de 1.542 pacientes foram randomizados para hidroxicloroquina e comparados com 3.132 pacientes randomizados apenas para os cuidados habituais. Não houve diferença significativa no desfecho primário da mortalidade em 28 dias (25,7\% para hidroxicloroquina vs. $23,5 \%$ dos cuidados usuais, $P=0,10)$. Também não houve evidência de efeitos benéficos na duração da internação hospitalar ou em outros resultados (RECOVERY, 2020).

Além disso, a utilização incorreta desta droga e a automedicação não previnem a Covid-19, podendo ser uma falsa sensação de proteção (DEVAUX et al., 2020; ZHOU; DAl; TONG, 2020). Além do mais, existem contraindicações à $\mathrm{HCQ}$, dentre as quais pacientes com maculopatias (retinopatias) preexistentes, hipersensibilidade aos derivados da 4-aminoquinolina e que utilizem anticoagulantes. Sugere-se, portanto, ampliação dos estudos para que se possam criar protocolos clínicos para a correta aplicação da HCQ em coronoviroses (DEVAUX et al., 2020; LIU et al., 2020), ou que venham a descartar a recomendação de seu uso para o tratamento de Covid-19.

\section{CONCLUSÕES}

Com base nos dados levantados no presente estudo, observou-se que a HCQ apresenta ainda resultados e conclusões controversos quanto aos bene- 
fícios de sua utilização para o tratamento da Covid-19, sendo, portanto, necessários estudos amplos com ensaios clínicos randomizados e cegos para fundamentar e orientar futuras intervenções clínicas para a mesma.

\section{REFERÊNCIAS}

BALEVIC, S. J. et al. Pharmacokinetics of Hydroxychloroquine in Pregnancies with Rheumatic Diseases. Clinical Pharmacokinetics, volume 58, p. 525-533, 2019.

BORBA, M. G. S. et al. Effect of High vs Low Doses of Chloroquine Diphosphateas Adjunctive Therapy for Patients Hospitalized With Severe Acute Respiratory Syndrome Coronavirus 2 (Sars-CoV-2) Infection a Randomized Clinical Trial. Jama Network Open, 3(4), 2020.

CHANG, R.; SUN, W. Repositioning Chloroquine as Ideal Antiviral Prophylactic against COVID-19 - Time is Now. Preprints, v. 1, 2020.

CHEN, Y.; LIU, Q.; GUO, D. Emerging coronaviruses: Genome structure, replication, and pathogenesis. Journal of Medical Virology, v. 92, 2020.

CHEW, C. Y. et al. Hydroxychloroquine in dermatology: New perspectives on an old drug. The Australasian College of Dermatologists, n. 2, 2019.

DEVAUX, C. A. et al. New insights on the antiviral effects of chloroquine against coronavirus: what to expect for COVID-19? International Journal of Antimicrobial Agents, Available on-line, 12 Mar. 2020.

DHAMA, K. et al. Coronavirus Disease 2019 - Covid-19. Preprints, 2020.

DYALL, J. et al. Middle East Respiratory Syndrome and Severe Acute Respiratory. Syndrome: Current Therapeutic Options and Potential Targets for Novel Therapies. Drugs, v. 77, p. 1.935-1.966, 2017.

ERKAN, D. et al. Hydroxychloroquine in the primary thrombosis prophylaxis of antiphospholipid antibody positive patients without systemic autoimmune disease. Lupus, 27, p. 399-406, 2018.

GAUTRET, P. et al. Hydroxychloroquine and azithromycin as a treatment of COVID-19: results of an open-label non-randomized clinical trial. International Journal of Antimicrobial Agents, Available on-line, 20 Mar. 2020.

GIWA, A.; DESAI, A. Novel Coronavirus COVID-19: An Overview for Emergency Clinicians. Emergency Medicine Practice EXTRA, Feb. 2020.

HUANG, C. et al. Clinical features of patients infected with 2019 novel Coronavirus in Wuhan, China. Lancet, 395, p. 497-506, 2020.

KUMAR, A. et al. Hydroxychloroquine Inhibits Zika Virus NS2B-NS3 Protease. ACS Omega, 3, p. 18.132-18.141, 2018.

LIU, J. et al. Hydroxychloroquine, a less toxic derivative of chloroquine, is effective in inhibiting SARS-CoV-2 infection in vitro. Cell Discovery, v. 6, n. 16, 2020.

MARMOR, M. F. Hydroxychloroquine During Cancer Therapy. Retinal Cases \& Brief Reports, Spring, v. 13, Issue 2, p. 95-97, 2019.

MALIK, Y. S. et al. Emerging novel coronavirus (2019-nCoV) - current scenario, evolutionary perspective based on genome analysis and recent developments. Journal Veterinary Quarterly, v. 40, 2020.
MERCURO, N. J. et al. Risk of QT Interval Prolongation Associated With Use of Hydroxychloroquine With or Without Concomitant Azithromycin Among Hospitalized Patients Testing Positive for Coronavirus Disease 2019 (Covid-19). Jama Cardiol., Published on-line, 1ㅇ May 2020.

MUNSTER, V. J. et al. A novel coronavirus emerging in China - key questions for impact assessment. N Engl J Med, 382, p. 692-694, 2020.

PERINEL, S. et al. Towards Optimization of Hydroxychloroquine Dosing in Intensive Care Unit COVID-19 Patients. Clinical Infectious Diseases, ciaa394, 2020.

PICOT, S. et al. Coalition: Advocacy for prospective clinical trials to test the post-exposure potential of hydroxychloroquine against COVID-19. One Health Available, on-line, 4 Apr. 2020.

PLANTONE, D.; KOUDRIAVTSEVA, T. Current and Future Use of Chloroquine and Hydroxychloroquine in Infectious, Immune, Neoplastic, and Neurological Diseases: A Mini-Review. Clinical Drug Investigation, v. 38, p. 653-671, 2018.

PONTICELLI, C.; MORONI, G. Hydroxychloroquine in systemic lupus erythematosus (SLE). Drug Safety Evaluation, p. 411-419, 2016.

RAMALINGAM, Kothai; BALASUBRAMANIAN, Arul. Novel Coronavirus: A mysterious threat from Wuhan, China - A current review. International Journal of Research in Pharmaceutical Sciences, 11(SPL1), p. 7-15, 2019.

RECOVERY. Randomised evaluation of Covid-19 therapy. Identificador NLM NCT04381936. Disponível em: https:// clinicaltrials.gov/ct2/show/NCT04381936. Acesso em: 8 jun. 2020.

ROWANE, N. et al. Rapid desensitization of hydroxychloroquine. Annals of Allergy, Asthma \& Immunology, v. 124, Issue 1, p. 97-98, 2020.

$\mathrm{SHI}$ N. et al. Protective effect of hydroxychloroquine on rheumatoid arthritis-associated atherosclerosis. Animal Model Exp Med., 2, p. 98-106, 2019.

$\mathrm{SHI}, \mathrm{T}$. T. et al. Research progress of hydroxychloroquine and autophagy inhibitors on câncer. Cancer Chemotherapy and Pharmacology, v. 79, p. 287-294, 2017.

SCHREZENMEIER, E.; DÖRNER, T. Mechanisms of action of hydroxychloroquine and chloroquine: implications for rheumatology. NaTure RevlewS, v. 16, Mar. 2020.

TANG, W. et al. Hydroxychloroquine in patients with mainly mild to moderate coronavirus disease 2019: open label, randomised controlled trial. BMJ, 369, 2020.

VERBAANDER, C. et al. Repurposing Drugs in Oncology (ReDO) - chloroquine and hydroxychloroquine as anti-cancer agentes. Ecancermedicalscience, 11, p. 781, 2017.

YAO, X. et al. In Vitro Antiviral Activity and Projection of Optimized Dosing Design of Hydroxychloroquine fortheTreatment of Severe Acute Respiratory Syndrome Coronavirus 2 (SARS-CoV-2). Clinical Infectious Diseases, v. 37, 2020.

ZHANG, T. et al. Clinical trials for the treatment of Coronavirus disease 2019 (COVID-19): A rapid response to urgent need. Science China Life Sciences, n. 12, 2020.

ZHOU, D.; DAI, S. M.; TONG, Q. Covid-19: a recommendation to examine the effect of hydroxychloroquine in preventing infection and progression. J Antimicrob Chemother, 2020.

ZVI, I. B.; KIVITY, S.; LAGEVITZ, P. Hydroxychloroquine: From Malaria to Autoimmunity. Clinical Reviews in Allergy \& Immunology, v. 42, p. 145-153, 2012. 